\title{
The Application of Psychological Contract in The College Office of Human Resources Management
}

\author{
Lanlan Liu \\ School of Economic and Management \\ Harbin University \\ Harbin China \\ e-mail: liulanlan_001@163.com
}

\author{
Qiang $\mathrm{Yu}$ \\ School of Economic and Management \\ Harbin University \\ Harbin China \\ e-mail: yuqiang0708@163.com
}

\begin{abstract}
The college office as school comprehensive management organization, and its management level directly related to the normal operation of the school each work. Effective psychological contract management can increase the sense of belonging to the organization staff, improve work enthusiasm. This article mainly from the psychological contract theory, Pertinently discusses the connotation and characteristics of the psychological contract, In-depth analysis of the college office the problems existing in the management, then made a more comprehensive discussion on how effectively constructs the strategy of the college office staff psychology contract.
\end{abstract}

Keywords-college office; management; organization staff; Psychological contract

The college office to ensure the normal operation of the school each work is very important role. It undertakes plan, communication, service, supervision, information transfer and other basic functions, its management scientific degree is directly related to the work of colleges levels of discretion. In addition, the scientific management of the college office for promoting the school each business and the harmonious development of the campus there are a very important significance. Modern management is people-centered management, college office management in the use of psychological contract theory, which can effectively achieve the modern management of human-oriented idea, fully display the individual talents and self-value, and enhance the overall function of the college office.

\section{THE MEANING AND CHARACTERISTICS OF THE PSYCHOLOGICAL CONTRACT}

"Psychological contract" concept was first introduced by Schein EH in its "Organizational Psychology" presented. " Psychological contract theory" is in recent years in western organizational behavior research and human resources management as a new theory .In Schein EH seems, An organization in a contractual relationship in fact there are two: one is the formal contract to form the economy of the text, the other is informal, not written in the text of the psychological contract, play an equally important with the economy contracts effect. The conclusion of the psychological contract, not only requires the individual to the organization's loyalty, dedication, and Except for the responsibility for the work on the job behavior, but also makes the constructing an organization positively. At the same time, the organization must recognize and respect the individual's justified rights, including giving them help, listen to their views, provide the necessary training and development, and Provisions on the rights of the individual and the protection which In the management of the organization's basic policies and rules. Although the psychological contract is intangible, but it's the same with tangible contract role, affecting between employees and the organization of mutual trust and understanding. Through the psychological contract intangible provisions It can make the individual and others within the organization in dynamic conditions, constantly continue to maintain a good relationship with the organization to fully consider themselves to be the main organization, and development of the individual development of fully integrated into the organization to create a dynamic organization always.

In other words, the meaning of constructing the psychological contract is that it is to realize the human ego development guarantee. The psychological contract has the following features:

\section{A. Informal}

Agreed that it is a subjective, exists in the consciousness without a clear and complete tool for expression and in a documented agreement. Most of the content of the psychological contract is a more abstract expression of the expectations, such as "be promoted"; or even a psychological feeling, as expected, "to be respected, trusted," and so on, there is no clear standard, the specific number of even accurate written expression.

\section{B. Dynamic development}

Formal contract of employment is generally stable, with little change. But the psychological contract is in a constant state of change and revision, it will with the relevant conditions, the ongoing changes in factors of reasonable adjustments in order to better stimulate their enthusiasm for work.

\section{Vulnerability}

Psychological contracts and performance relies on both good communication and mutual trust and integrity, such as either intentionally or unintentionally ignored, missed or misinterpreted by the other parties to this contract understand the rights and obligations and requirements, then this difficult to really set up a contract or a real performance. 


\section{Objectivity}

Although the psychological contract has not added implicit expectations of each other, but after a certain period of learning and social adaptation, the employees and the organization will have strong expectations of each other, in this sense, the psychological contract is real.

\section{The Management Problems OF UnIVERsity OFFICE}

\section{A. Quality management concepts and needs to be improved}

For a lone time, the main focus of the management concept and the system of property management, the neglect of people management, neglect of the management of human creativity, which has greatly hindered the improvement of the quality of management. In modern society, talent is the primary factor in modern management, university management office managers determine the level of the Office of the level of execution. Therefore, the college office managers must establish a people-oriented management philosophy, with a correct political orientation, position and point of view, to establish a scientific world outlook and values, to take the initiative to adapt to new situation, enhance the management level.

\section{B. The functions and objectives are so vague of the university office work}

Office is the university college will be established institutions, compared with other functional departments, the University Office work more arduous. It should be bearing on, but also start the next, but also horizontal linkages; not only to participate in the government, but also management issues. In practice, the University Office often in a passive state. A staff member whose functions and objectives for their work without reasonable understanding of the work often resulting in the lack of initiative, and focused work plan is not strong, the working state of disorder, the overall efficiency is not high, slowly increase the level of work.

\section{The workers of university office lack of self- improvement way}

The overall culture of the university management of high-quality environment, the college office staff focus more on self-realization. Higher quality office staff is mainly reflected in political quality, professional ability and style of work in three aspects. As usual most of the time office staff busy with all kinds of things, it is difficult to conduct systematic study of political theory, it is their lack of career awareness and career planning, it is difficult to selfimprovement. Also very few schools provide training, education opportunities, so neglect learning, part of the longterm stay in office staff, The lack of competition, effective management, causing them to work hard to get the sense of accomplishment, and individual staff will be completed because of not satisfied with the general affairs passive, resulting in non-office work at ease, endless longing to the outside world.

\section{D. complexity of the work environment}

Most university staff from the Office of cadres, counselors, teachers, supplementary team elected or retained school graduates, who is relatively complex. Office staff communication capabilities, such as communication skills, public relations skills, adaptability to difficult to achieve the same standards and requirements, if the university within the Office of the lack of effective communication and good atmosphere, its staff may be negative and negative emotions. Meanwhile, the college office staff to serve primarily the work of the nature of university leadership, they often give rise to some colleagues thought the high production quality is not envy, therefore, often by the University Officers departmental staff around the various ways of attack.

\section{THE PSYCHOLOGICAL CONTRACT MANAGEMENT ON THE SIGNIFICANCE OF UNIVERSITY OFFICE}

\section{A. Conducive to a clear development goals of the University Officers}

Conducive to psychological contract management staff of the Office of University Development and the department of career development, continuing balance, stimulate the inherent potential and enthusiasm. College Office Staff are generally well-received professional education and training, with the characteristics of knowledge workers; they usually have a personalized, diversified and innovative features; have a high professional knowledge and skills at work has a strong autonomy, a strong desire for achievement, willingness to accept challenging work, good self-worth by learning to pursue the realization of sustainable development and life skills. Psychological contract can induce the invisible contract staff continued to examine the psychological expectations of their own career development and sector development, promote staff changes in a dynamic environment and constantly adjust their own behavior, take ownership of being involved in office management, and consciously initiative to achieve personal self-development, personal development in order to maintain consistency with the sector development objectives, and career development and sector development closely linked together, to maintain a high degree of loyalty to the department. For example, when the college office staff aware of existing work can give him a higher salary, promotion opportunities, vocational training and job enrichment and other commitments, it will be for the sector development and contribute their skills and loyalty, and as a return to the department of organization, but also with the department an equal exchange.

\section{$B$. help improve the incentive effect, reducing management costs}

From the perspective of Nature inspired, organized mainly to meet the staff incentive psychological needs of the construction of psychological contract can more effectively meet the psychological needs of knowledge workers and improve the incentive effect, thereby reducing the organization's management costs, improve management efficiency. 


\section{C. reduce unnecessary conflicts at work, and enhance the internal cohesion of the school}

The conclusion of the psychological contract can be constructed to maximize the people-oriented work culture, people do their best to achieve, people make the best use to achieve the ideal combination of people and events, to maximize the elimination of unnecessary contradictions and conflicts, especially psychological and conceptual conflict. Resulting in the formation of work in unity within the school, cohesive situation.

\section{EFFECTIVE CONSTRUCTION OF THE PSYCHOLOGICAL CONTRACT STAFF OF THE OFFICE'S STRATEGY}

Psychological Contract Management University Office as the dominant party, its management goals is whether to establish a balanced psychological contract, while monitoring changes in the psychological contract, development, and through changes in methods and content to maintain and change the office psychological contract staff to perform, in order to achieve the psychological contract between the two dynamic balance. Therefore, the University Office of the psychological contract model is constructed in accordance with the specific characteristics of the psychological contract of its formation, development, change process and the active intervention of the complete system. As shown, a complete psychological contract management system, established by the contract, contractual adjustments and, ultimately, three management modules, while a few links and interactions between, and promote each other to achieve objectives of the psychological contract homeostasis.

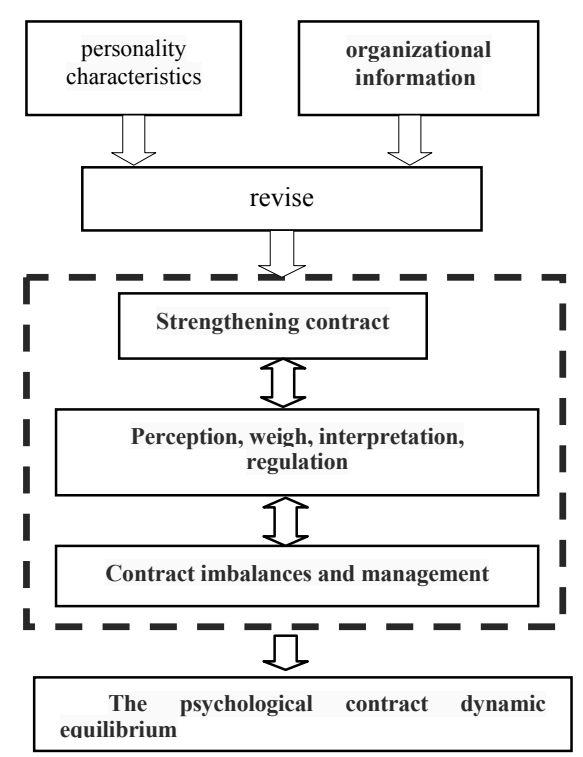

Fig.1. College Office of the psychological contract management process and structure

\section{A. the establishment of psychological contract}

1) Further clear function and goal, implement scientific career management, office staff for colleges to create valuable "vision"

The conclusion of the psychological contract managers on the management of higher requirements. As a manager should be people-oriented flexible management, and as members of the department to improve solidarity and cohesion. Concrete work, management guidelines were laid in the overall tone of the work of University Office, and the controlled tracking and adjustment. Avoid by injunction, by the authority to maintain the superior-subordinate relationship. Only when reporting relationships tend to work relationships. Both tend to become a contractual relationship is possible between the Covenant and the treaty. Contract concluded in the heart of the beginning of each of the department managers should be aware of the expertise of staff and work expectations of cards. Configuration to optimize the workforce on the one hand, the rationalization of the division of duties to do himself or herself, and the status of this sector and the development of the next few years and development goals, to help staff a reasonable person is expected to promote their convergence in the sector expected. If communication expertise to the officer in charge of outreach work, good at his writing staff can be engaged in clerical and archival work. While encouraging staff to build personal career planning, and establish-stage goal achievement plan, annual development plans compatible with the department.

2) build trust and intimacy with the harmonious organization culture atmosphere 。

University Office should focus on good humanistic flexible management model. A viable management system, you need to infection and inspire all who maintained the faith and spirit of the noble, and has to meet the emotional needs of all the staff of the harmonious atmosphere. Colleges and universities to implement management of the psychological contract, must be established with a strong cultural atmosphere of the modern organization culture that cultural values should enable the organization to establish a real focus on human capacity and the demand on the basis of a reasonable and allow staff to have equal sense and sense of responsibility, the development of the department willing to give their loyalty and ability. The only way to enhance the office workers sense of team unity and cooperation.

3) using various means of incentive, mining and inspire people's potential ability

For college office workers are concerned, the reasonable incentive mechanism to stimulate belongingness and identification. The principle of reciprocity is based, on the analysis of the incentive judge staff based on the real needs, the design gives appropriate incentive system. Material terms, we should respect the basis of the characteristics of needs, developing a based on knowledge, skills and performance and different forms of multidimensional standard of incentive measures. The concrete measures include benefits salary, bonus, salary, skills transfer, promotion, post title work environment incentive, etc. In terms of mental and 
spiritual demand because of the individual with the time, place and conditions of such as changes, so only good at finding and stimulate personal interests motives and promptly formulate targeted measures to meet, attain spiritual incentive is effective. This requires the managers of the strengthening and work personnel's communication, understand their specialty, expectations and work target, etc, grasps the staff's current needs, wishes or the motivation, at the right time, arrange for its tailored has incentive characteristics, according to work, targeted implement incentive. Main measures including target motivation, participation motivation, organization incentive and training education incentive, etc

\section{B. Adjustment of the psychological contract}

University Office managers to track the trajectory of the psychological staff, timely management of the psychological contract. On the one hand should continue to build a psychological contract, organizational commitment that managers can use the re-engineering, department organizational change, career planning, training and new incentives to guide the faithful under the psychological contract further. Meanwhile, in order to prevent the psychological contract violation, when the reality and predict deviations occur, the effectiveness of the work is not high, or have mistakes, and managers should actively communicate effectively, to weaken or eliminate the psychological burden on staff and reduce the negative impact. As a result of certain comrades have low emotional intensity of work, leaders should consider re-division of rationality and rationalization of work and listen to personal opinion, the line of interpretation, adjusted within the range of the executable to reduce the work due to the difficulty of discontent .

\section{Implementation of psychological contract}

Office of University administrators should be promptly investigated the degree of psychological contract fulfillment, office staff know to what extent the psychological contract has become a reality, such as: whether job satisfaction? The availability of promotion opportunities? In achieving their goals difficulties encountered in the ability of individual problem or sector. If this clearly and managers can analyze and propose effective solutions, then the University Office of the psychological contract can be sustained in the interaction between individuals and departments in the balance.

Anyhow, people-oriented harmonious socialist society construction is the core idea, is the core idea of school management. Universities in the school each work office plays a pivotal role. College office managers only continuously probe management theory, use the psychological contract theory, humanist, fully mobilize the enthusiasm of working personnel play their master spirit, can cause the management work to improve to a new level, making college office management really took to the humanity, ordering and scientific orbit.

\section{REFERENCES}

[1] Rousseau, D. M. \& Tijoriwala.Perceived leg itim acy \& unila tera 1 contract changes: It takes a good reason to change a psychological con tract [ R ].Symposium at the SIOP meetings, San Diago, 1996, Ap ril.

[2] Lee, C., Tinsley, C. H. Psychologica normative contracts of work group member in the US and Hong Kong [ R ]. Working Paper, 1999.

[3] Conway,N.Briner,R.B.UnderstandingPsyehologyieal Contraets atWork:a Critieal Evaluation of Therory and Researeh,OxfordUneversity Pres, 2005

[4] Suhua Qian, Universities need more flexible management in the new century. Journal of Yunnan Normal U niversity, Vol. 33 No. ,Nov. 2001

[5] Xiaoying Song. People-oriented Management to Enhance the Effectiveness of the Office in the University, Value Engineering, Vol . 29 No. 29 ,pp.187-188, Feb.2010 . 